\title{
Height growth velocity, islet autoimmunity and type 1 diabetes development: the Diabetes Autoimmunity Study in the Young
}

\author{
M. M. Lamb • X. Yin • G. O. Zerbe • \\ G. J. Klingensmith • D. Dabelea • T. E. Fingerlin • \\ M. Rewers • J. M. Norris
}

Received: 3 February 2009 /Accepted: 1 June 2009 /Published online: 23 June 2009

(C) Springer-Verlag 2009

\begin{abstract}
Aims/hypothesis Larger childhood body size and rapid growth have been associated with increased type 1 diabetes risk. We analysed height, weight, BMI and velocities of growth in height, weight and BMI, for association with development of islet autoimmunity (IA) and type 1 diabetes.

Methods Since 1993, the Diabetes Autoimmunity Study in the Young (DAISY) has followed children at increased type 1 diabetes risk, based on HLA-DR, -DQ genotype or family history, for the development of IA and type 1 diabetes. IA was defined as the presence of autoantibodies to insulin, GAD or protein tyrosine phosphatase islet antigen 2 twice in succession, or autoantibody-positive on one visit and diabetic at the next consecutive visit within 1 year. Type 1 diabetes was diagnosed by a physician. Height and weight were collected starting at age 2 years. Of 1,714 DAISY children $<11.5$ years of age, 143 developed IA and 21 progressed to type 1 diabetes. We conducted Cox proportional hazards analysis to explore growth velocities and size measures for association with IA and type 1 diabetes development.
\end{abstract}

Electronic supplementary material The online version of this article (doi:10.1007/s00125-009-1428-2) contains supplementary material, which is available to authorised users.

M. M. Lamb $\cdot$ X. Yin · G. O. Zerbe $\cdot$ D. Dabelea $\cdot$

T. E. Fingerlin $\cdot$ M. Rewers $\cdot$ J. M. Norris $(\square)$

Colorado School of Public Health,

University of Colorado Denver,

13001 East 17th Place, Box B-119, Aurora, CO 80045, USA

e-mail: Jill.Norris@ucdenver.edu

G. J. Klingensmith $\cdot$ M. Rewers

Barbara Davis Center for Childhood Diabetes,

Aurora, CO, USA
Results Greater height growth velocity was associated with IA development (HR 1.63, 95\% CI 1.31-2.05) and type 1 diabetes development (HR 3.34, 95\% CI 1.73-6.42) for a 1 SD difference in velocity.

Conclusions/interpretation Our study suggests that greater height growth velocity may be involved in the progression from genetic susceptibility to autoimmunity and then to type 1 diabetes in pre-pubertal children.

Keywords Childhood height $\cdot$ Height growth velocity Islet autoimmunity · Type 1 diabetes
Abbreviations
BLUP Best linear unbiased predictor
DAISY Diabetes Autoimmunity Study in the Young
IA
Islet autoimmunity
IA2 Protein tyrosine phosphatase islet antigen 2

\section{Introduction}

Type 1 diabetes is an autoimmune disease in which the insulin-producing beta cells of the pancreas are destroyed. A long preclinical phase of islet autoimmunity (IA) often precedes the clinical diagnosis of type 1 diabetes. Children progress from IA to type 1 diabetes at different rates $[1,2]$, and it is still unknown whether or not all children who develop IA will eventually develop type 1 diabetes. Identifying the predictors of IA and type 1 diabetes might shed light on the biological mechanisms that influence the early stages of this autoimmune disease process.

Two recent hypotheses are that the current childhood obesity epidemic is driving the increasing incidence and earlier age of type 1 diabetes onset seen around the world 
[3-6]. The 'overload hypothesis' [7] suggests that the high insulin demand on the beta cell that results from the overfeeding and resultant accelerated growth of today's youth makes the beta cells vulnerable to autoimmune attack and apoptosis. The 'accelerator hypothesis' suggests that insulin resistance caused by excess weight gain may accelerate beta cell apoptosis in individuals at genetic risk [8].

Ecological studies have suggested a correlation between increasing BMI, weight and height and incidence of type 1 diabetes in the population [9, 10]. Several studies have shown an association between higher BMI SD scores and earlier age at diagnosis of type 1 diabetes [11-14], although others have not [15-17]. In case-control studies, children with type 1 diabetes showed increased weight, height or BMI SD scores compared with non-diabetic children in either infancy or early childhood [18-26]. Analysis of a birth cohort suggested that increased BMI in childhood increased risk of self-reported type 1 diabetes [27]. A recent study examined this in a cohort of children at increased risk of type 1 diabetes and found that higher weight and BMI SD scores were associated with development of IA [28]. Childhood obesity and rapid growth may trigger autoimmunity by creating higher insulin demands on the pancreas, which may make the beta cell more active and more visible to the immune system. Higher insulin demands might also exacerbate autoimmunity by stressing beta cells already under autoimmune attack. We used a prospective cohort of healthy children aged 2-11 years who were at increased genetic risk of type 1 diabetes, to explore the association of childhood size and growth rate with two outcomes: earlier IA development and more rapid progression to type 1 diabetes in those with evidence of IA.

\section{Methods}

The Diabetes Autoimmunity Study in the Young (DAISY) is a prospective study of three groups of young children at increased risk of developing type 1 diabetes. One group consists of unaffected first-degree relatives of patients with type 1 diabetes, identified and recruited between birth and age 8 years through the Barbara Davis Center for Childhood Diabetes in Denver, Colorado, other diabetes care clinics and the Colorado IDDM Registry. The second group consists of babies born at St Joseph's Hospital in Denver, CO, USA, and screened by umbilical cord blood samples for diabetes-susceptibility alleles in the HLA region. The third group is composed of siblings of the second (newborn-screened) group, who are also screened and enrolled into DAISY and followed for the development of autoimmunity and type 1 diabetes. The details of the newborn screening [29] have been published elsewhere.
DAISY enrolled over 2,600 children from 1993 to 2004. The Colorado Multiple Institutional Review Board approved all study protocols, and informed consent was obtained from the parents/legal guardians of all children.

HLA genotype status of the child was determined from a cord blood sample, if obtained at birth, or from blood drawn at the first clinic visit. Blood was sent to Roche Molecular Systems, Alameda, CA, USA for PCR-based HLA class II typing. The high-risk HLA-DR, -DQ genotype was defined as $D R B 1 * 03 / D R B 1 * 04$, $D Q B 1 * 0302$. Prospective follow-up of DAISY children included testing for autoantibodies to insulin, protein tyrosine phosphatase islet antigen 2 (IA2) and GAD at clinic visits at 9, 15 and 24 months (if the child was enrolled at birth) or at enrolment visit (if the child was enrolled later in childhood), and annually thereafter up to age 15 years. GAD autoantibodies and IA2 autoantibodies were measured with a combined radiobinding assay [30, 31]. Insulin autoantibody was measured by a micro-insulin autoantibody assay as described previously [31, 32].

The outcome of IA was defined as the presence of autoantibodies to insulin, GAD or IA2 at two consecutive clinic visits, or autoantibody-positive on one visit and diabetic on the next consecutive visit within 1 year. The age at the first of two consecutive IA-positive visits, or the age at the IA-positive visit that was followed by type 1 diabetes diagnosis within 1 year, was used as the age at IA development (i.e. in the time-to-event analyses). Children who were positive for one or more autoantibodies were examined every 3-6 months, and $\mathrm{HbA}_{1 \mathrm{c}}$ and random glucose were also measured. A child was referred to a physician for type 1 diabetes diagnosis if they had a random glucose $>11.1 \mathrm{mmol} / 1$ and/or an $\mathrm{HbA}_{1 \mathrm{c}}>6.2 \%$. The criteria used for diagnosis included typical symptoms of polyuria and/or polydipsia and a random glucose $>11.1 \mathrm{mmol} / 1$ or an OGTT with a fasting plasma glucose of $>6.9375 \mathrm{mmol} / 1$ or a $2 \mathrm{~h}$ glucose $>11.1 \mathrm{mmol} / \mathrm{l}$. Details of the intensive monitoring and diagnosis protocol have been described previously [33]. The age at physician diagnosis was used as the age at type 1 diabetes development (i.e. in the time-to-event analyses).

Sex, race/ethnicity, maternal education and household income were collected in an interview at the time of enrolment. Weight was measured at every clinic visit on a scale with a precision of $\pm 0.1 \mathrm{~kg}$. Height was first measured when the child was able to stand cooperatively, about 2 years old, and at every clinic visit thereafter, using a stadiometer with a precision of $\pm 1 \mathrm{~mm}$. BMI was calculated as weight $(\mathrm{kg}) /$ height $(\mathrm{m})^{2}$ for all clinic visits where the child was at least 2 years old.

These analyses are limited to children who developed IA or type 1 diabetes after the age of 2 years, the age at which we first obtained height measurements. Because puberty is 
a time of increased insulin resistance resulting from very rapid growth rate and dramatic hormonal changes [34], we analysed records collected prior to age 11.0 years for girls, and prior to age 11.5 years for boys. These age cut-offs represent the median ages at which a sample of DAISY children $(n=604)$ reported being at Tanner stage 2 on a Tanner self-staging questionnaires [35].

Cohort for the analysis of the development of IA

In order to explore associations between childhood size, growth rate and time to IA development, we analysed DAISY children for whom at least two height and weight measures were available (9,914 records on 1,714 children) prior to or at IA development. Seventy-five of the 1,714 children developed IA during follow-up.

Cohort for the analysis of the development of type 1 diabetes in autoimmune children

To explore associations between childhood body size, growth rates and type 1 diabetes development, we analysed 143 autoimmune children for whom at least two height and weight measurements were collected at least 3 months prior to type 1 diabetes diagnosis. Twenty-one children developed type 1 diabetes. These 143 IA-positive children included 73 of the children who developed IA during the study, 32 who developed autoantibodies before age 2 years, and 39 who had autoantibodies at their first clinic visit.

Children often lose weight rapidly just prior to type 1 diabetes diagnosis. We did not want to include data that may have been influenced by the disease prodrome, rather than acting as a potential predictor of the disease. Therefore, we did not use the height and weight measurements collected within 3 months of type 1 diabetes diagnosis, and instead extrapolated these values based on our models, as described in the statistical analysis section below.

\section{Statistical analyses}

In order to get an accurate picture of each child's overall growth experience, we first produced graphs of growth values for individual children, as well as population means, of height, weight and BMI, at each age (in years). Next, we fitted mixed models of the best-fitting polynomials for the fixed effects and for the random effects of height, weight and BMI on age for each sex. This method is described in Fitzmaurice et al. [36] and an example of the use of this method can be found in Sontag et al. [37]. The best-fitting mixed models produced estimates of the mean growth curves as well as best linear unbiased predictors (BLUPs) for individual participants' growth curves with respect to height, weight and BMI. BMI throughout childhood in this cohort was best represented by second-degree polynomials in the fixed effects and random effects. Height and weight gain patterns in this cohort were linear in both the fixed and random effects.

BLUPs of individuals' growth curves were evaluated at each clinic visit, including records where height, weight or BMI were missing. Plots indicated that the BLUP curves closely fitted the raw data. Using BLUPs allowed us to disregard the height and weight measures within 3 months of type 1 diabetes diagnosis, and instead extrapolate these values for clinic visits close to diagnosis, when the disease process itself may be affecting body size. BLUPs also allowed us to interpolate body size values that were missing, as either height or weight was not measured in about $7 \%$ of the clinic visits. The first derivatives of the polynomial equations used to calculate the above growth curves gave BLUPs of the instantaneous growth velocities for height, weight and BMI at each clinic visit. The instantaneous growth velocity of BMI varied over time, while the instantaneous growth velocities of height and weight were constant for each child. Cox proportional hazards models allowed us to examine the BLUPs of height, weight, BMI and instantaneous velocity of BMI as time-varying covariates for association with IA, and for association with type 1 diabetes in children with IA. HRs were calculated for a $1 \mathrm{SD}$ difference in velocity. BLUPs of instantaneous height growth velocity and instantaneous weight growth velocity were analysed as fixed covariates, because height and weight growth velocity remained constant over age. All models were adjusted for ethnicity (non-Hispanic white or other), HLA-DR, -DQ genotype (high-risk or not) and family history of type 1 diabetes. Analyses with type 1 diabetes as the outcome were also adjusted for the age at which the first autoantibody was detected. All statistical modelling and analyses were conducted using SAS version 9.1 (SAS Institute, Cary, $\mathrm{NC}$, USA).

The term 'instantaneous growth velocity' refers to growth velocity, i.e. change in size per unit time, as the unit of time approaches zero. For ease of presentation, we refer to these variables simply as growth velocity rather than instantaneous growth velocity throughout the remainder of the manuscript.

\section{Results}

Height, weight, BMI and growth velocity in the DAISY cohort

As shown in cross-sections of the DAISY cohort (Table 1), estimates of height and weight are higher in the older age 
Table 1 Size and growth velocities in 3-, 5- and 8-year-old children in DAISY
Values are means $\pm \mathrm{SD}$

${ }^{a}$ BLUP estimates of height, weight and BMI

\begin{tabular}{llll}
\hline Variable & \multicolumn{3}{l}{ Age (years) } \\
\cline { 2 - 4 } & 3 & 5 & 8 \\
\hline$n$ & 1,319 & 1,140 & 796 \\
Height $(\mathrm{cm})^{\mathrm{a}}$ & $97.06 \pm 4.25$ & $110.94 \pm 4.78$ & $130.86 \pm 5.95$ \\
Weight $(\mathrm{kg})^{\mathrm{a}}$ & $14.78 \pm 1.68$ & $20.34 \pm 2.95$ & $29.44 \pm 5.90$ \\
BMI $\left(\mathrm{kg} / \mathrm{m}^{2}\right)^{\mathrm{a}}$ & $16.04 \pm 1.08$ & $15.85 \pm 1.42$ & $16.83 \pm 2.38$ \\
Height growth velocity (cm/year) & $6.84 \pm 0.54$ & $6.75 \pm 0.56$ & $6.63 \pm 0.57$ \\
Weight growth velocity (kg/year) & $2.78 \pm 0.84$ & $2.81 \pm 0.91$ & $2.96 \pm 1.01$ \\
BMI growth velocity $\left(\mathrm{kg} \mathrm{m}{ }^{-2}\right.$ year $\left.^{-1}\right)$ & $-0.26 \pm 0.29$ & $0.08 \pm 0.32$ & $0.58 \pm 0.47$ \\
\hline
\end{tabular}

groups. BMI is stable or slightly decreases between ages 3 and 5 years, and then is increased at age 8 years, suggestive of adiposity rebound [38]. Growth velocity of BMI is negative in the 3- and 5-year olds, suggesting a slow-down of growth in BMI. In 8-year-olds, the BMI growth velocity is positive, reflecting increasing growth in the older ages. The growth velocities of height and weight were similar in 3-, 5- and 8-year-olds.

Analysis of the development of IA in children at increased risk of type 1 diabetes

Seventy-five of the 1,714 DAISY children in this analysis developed IA, at a mean age of 6.6 years (Table 2). The minimum number of size measurements per child in this analysis was two, the median was five, and the maximum was 16. Mean heights, weights and BMIs by age of children who did and did not become IA-positive are presented in Electronic supplementary material (ESM) Fig. 1. Adjusting for ethnicity, HLA-DR, -DQ genotype and family history of type 1 diabetes, greater height growth velocity was strongly associated with IA development (Table 2). Height and weight were also inversely associated with IA development, although the associations were weaker, particularly for weight. Height was inversely correlated with height growth velocity in these children (Pearson $r=-0.09, p=0.0007$ ). When both height and height growth velocity were included in the model together,

Table 2 Analysis of the relationship between body size and growth and the development of IA in children at increased risk of type 1 diabetes

\begin{tabular}{|c|c|c|c|}
\hline Variable & $\begin{array}{l}\text { Developed IA } \\
(n=75)\end{array}$ & Did not develop IA $(n=1,639)$ & $\operatorname{HR}(95 \% \mathrm{CI})$ \\
\hline High-risk HLA-DR, -DQ genotype & $34.7(n=26)$ & $19.5(n=319)$ & $2.13(1.32-3.42)$ \\
\hline Family history of type 1 diabetes & $57.3(n=43)$ & $48.0(n=786)$ & $1.44(0.91-2.28)$ \\
\hline Female & $53.3(n=40)$ & $47.4(n=777)$ & $1.29(0.82-2.04)^{\mathrm{a}}$ \\
\hline Non-Hispanic white ethnicity & $80.0(n=60)$ & $75.6(n=1,239)$ & $1.12(0.63-2.00)^{\mathrm{a}}$ \\
\hline Maternal education $>12$ years $(n=1,656)$ & $83.8(n=62)$ & $78.6(n=1,244)$ & $1.36(0.73-2.52)^{\mathrm{a}}$ \\
\hline Annual income $\geq \$ 30,000(n=1,617)$ & $76.4(n=55)$ & $76.9(n=1,188)$ & $1.01(0.58-1.74)^{\mathrm{a}}$ \\
\hline Age at first autoantibody-positive visit or most recent visit (years) & $6.63 \pm 2.39$ & $7.91 \pm 2.71$ & - \\
\hline Height $(\mathrm{cm})^{\mathrm{b}}$ & $\mathrm{N} / \mathrm{A}^{\mathrm{c}}$ & $\mathrm{N} / \mathrm{A}^{\mathrm{c}}$ & $0.34(0.16-0.72)^{\mathrm{d}}$ \\
\hline Weight $(\mathrm{kg})^{\mathrm{b}}$ & $\mathrm{N} / \mathrm{A}^{\mathrm{c}}$ & $\mathrm{N} / \mathrm{A}^{\mathrm{c}}$ & $0.61(0.39-0.98)^{\mathrm{d}}$ \\
\hline BMI $\left(\mathrm{kg} / \mathrm{m}^{2}\right)^{\mathrm{b}}$ & $\mathrm{N} / \mathrm{A}^{\mathrm{c}}$ & $\mathrm{N} / \mathrm{A}^{\mathrm{c}}$ & $0.99(0.80-1.21)^{\mathrm{d}}$ \\
\hline Height growth velocity (cm/year) & $6.96 \pm 0.45$ & $6.78 \pm 0.55$ & $1.63(1.31-2.05)^{\mathrm{d}}$ \\
\hline Weight growth velocity (kg/year) & $2.80 \pm 0.70$ & $2.80 \pm 0.87$ & $0.88(0.69-1.11)^{\mathrm{d}}$ \\
\hline BMI growth velocity $\left(\mathrm{kg} \mathrm{m}^{-2}\right.$ year $\left.^{-1}\right)$ & $\mathrm{N} / \mathrm{A}^{\mathrm{c}}$ & $\mathrm{N} / \mathrm{A}^{\mathrm{c}}$ & $0.88(0.64-1.21)^{\mathrm{d}}$ \\
\hline
\end{tabular}

Values are $\%$ or means \pm SD

${ }^{a}$ HRs adjusted for HLA-DR, -DQ genotype and family history of type 1 diabetes

${ }^{\mathrm{b}}$ BLUP estimates of height, weight or BMI

${ }^{\mathrm{c}}$ Not applicable because of the time-varying nature of the data. See Table 1 for details regarding these variables

${ }^{\mathrm{d}}$ HRs for a 1 SD difference, adjusted for ethnicity, HLA-DR, -DQ genotype and family history of type 1 diabetes. The SDs for height, weight, BMI, height growth velocity, weight growth velocity and BMI growth velocity were $17.84,8.67,1.99,0.57,0.93$ and 0.57 , respectively 
the estimates were HR 0.01 (95\% CI 0.002-0.02) for height and HR $5.26(95 \%$ CI 3.77-7.33) for height growth velocity.

Analysis of the development of type 1 diabetes in autoimmune children

This analysis included 143 children who had developed IA, of whom 21 developed type 1 diabetes. All children had at least two height and weight measurements at or after the development of IA. Those who developed type 1 diabetes had at least two height and weight measurements collected at least 3 months prior to type 1 diabetes diagnosis. The minimum number of size measurements per child in this analysis was two, the median was seven, and the maximum was 31 . Mean heights, weights and BMIs by age of IApositive children who did and did not develop type 1 diabetes are presented in ESM Fig. 2. The 21 children who developed diabetes had a mean IA development age of 2.32 years (compared with 5.29 years in those who had not developed diabetes during follow-up), and developed type 1 diabetes at a mean age of 6.86 years (Table 3 ).

In models adjusted for age at the first autoantibody-positive visit, ethnicity, HLA-DR, -DQ genotype and family history of type 1 diabetes, greater height growth velocity was strongly associated with progression to type 1 diabetes (HR 3.34, 95\% CI 1.73-6.42) for a 1 SD difference in velocity in children with autoimmunity. Height, weight, BMI, weight growth

Table 3 Analysis of the relationship between body size and growth and the development of type 1 diabetes in autoimmune children at increased risk of type 1 diabetes

\begin{tabular}{|c|c|c|c|}
\hline Variable & $\begin{array}{l}\text { Progressed to diabetes }(n= \\
\text { 21) }\end{array}$ & $\begin{array}{l}\text { Did not progress to diabetes }(n= \\
122)\end{array}$ & $\operatorname{HR}(95 \% \mathrm{CI})$ \\
\hline High-risk HLA-DR, -DQ genotype & $52.4(n=11)$ & $27.1(n=33)$ & $\begin{array}{l}2.14(0.91- \\
5.06)\end{array}$ \\
\hline Family history of type 1 diabetes & $71.4(n=15)$ & $52.5(n=64)$ & $\begin{array}{l}2.02(0.78- \\
5.23)\end{array}$ \\
\hline Female & $47.6(n=10)$ & $48.4(n=59)$ & $\begin{array}{l}1.51(0.62- \\
3.64)^{\mathrm{a}}\end{array}$ \\
\hline Non-Hispanic white ethnicity & $85.7(n=18)$ & $82.0(n=100)$ & $\begin{array}{l}0.54(0.15- \\
1.90)^{\mathrm{a}}\end{array}$ \\
\hline Maternal education $>12$ years $(n=138)$ & $71.4(n=15)$ & $81.2(n=95)$ & $\begin{array}{l}0.81(0.30- \\
2.18)^{\mathrm{a}}\end{array}$ \\
\hline Annual income $\geq \$ 30,000(n=133)$ & $75.0(n=15)$ & $77.9(n=88)$ & $\begin{array}{l}0.60(0.19- \\
1.93)^{\mathrm{a}}\end{array}$ \\
\hline IA development age (years) & $2.32 \pm 1.78$ & $5.29 \pm 2.97$ & $\begin{array}{l}0.84(0.64- \\
1.09)^{\mathrm{a}}\end{array}$ \\
\hline $\begin{array}{l}\text { Age at type } 1 \text { diabetes development or most recent visit } \\
\text { (years) }\end{array}$ & $6.86 \pm 2.12$ & $8.80 \pm 2.58$ & - \\
\hline Height $(\mathrm{cm})^{\mathrm{b}}$ & $\mathrm{N} / \mathrm{A}^{\mathrm{c}}$ & $\mathrm{N} / \mathrm{A}^{\mathrm{c}}$ & $\begin{array}{l}0.98(0.22- \\
4.36)^{\mathrm{d}}\end{array}$ \\
\hline Weight $(\mathrm{kg})^{\mathrm{b}}$ & $\mathrm{N} / \mathrm{A}^{\mathrm{c}}$ & $\mathrm{N} / \mathrm{A}^{\mathrm{c}}$ & $\begin{array}{l}0.88(0.33- \\
2.32)^{\mathrm{d}}\end{array}$ \\
\hline BMI $\left(\mathrm{kg} / \mathrm{m}^{2}\right)^{\mathrm{b}}$ & $\mathrm{N} / \mathrm{A}^{\mathrm{c}}$ & $\mathrm{N} / \mathrm{A}^{\mathrm{c}}$ & $\begin{array}{l}1.12(0.70- \\
1.81)^{\mathrm{d}}\end{array}$ \\
\hline Height growth velocity (cm/year) & $7.16 \pm 0.49$ & $6.62 \pm 0.64$ & $\begin{array}{l}3.34(1.73- \\
6.42)^{\mathrm{d}}\end{array}$ \\
\hline Weight growth velocity (kg/year) & $2.74 \pm 1.34$ & $3.17 \pm 1.22$ & $\begin{array}{l}1.01(0.58- \\
1.77)^{\mathrm{d}}\end{array}$ \\
\hline BMI growth velocity $\left(\mathrm{kg} \mathrm{m}^{-2}\right.$ year $\left.^{-1}\right)$ & $\mathrm{N} / \mathrm{A}^{\mathrm{c}}$ & $\mathrm{N} / \mathrm{A}^{\mathrm{c}}$ & $\begin{array}{l}1.28(0.79- \\
2.08)\end{array}$ \\
\hline
\end{tabular}

Values are $\%$ or means \pm SD

${ }^{a}$ HRs adjusted for age at first autoantibody-positive visit, HLA-DR, -DQ genotype and family history of type 1 diabetes

${ }^{\mathrm{b}}$ BLUP estimates of height, weight or BMI

${ }^{\mathrm{c}}$ Not applicable because of the time-varying nature of the data. See Table 1 for details regarding these variables

${ }^{\mathrm{d}}$ HRs for a 1 SD difference, adjusted for age at first autoantibody-positive visit, ethnicity, HLA-DR, -DQ genotype and family history of type 1 diabetes. The SDs for height, weight, BMI, height growth velocity, weight growth velocity and BMI growth velocity were 18.19, 9.26, 2.05, 0.68, 1.14 and 0.58 , respectively 
velocity and BMI growth velocity were not associated with more rapid progression to type 1 diabetes in autoimmune children (Table 3).

\section{Discussion}

In this analysis of children at increased genetic risk of type 1 diabetes, greater height growth velocity was associated with earlier IA development in healthy children, and was even more strongly associated with more rapid progression to type 1 diabetes in autoimmune children. Shorter height and lower weight were weakly associated with IA development, but were not associated with progression to type 1 diabetes in IA-positive children. BMI and growth velocities of weight and BMI were not associated with either IA development or progression to type 1 diabetes.

Many of the previous studies had used SD scores for height, weight and BMI, calculated from general population data for the analysis of association with type 1 diabetes, using a case-control design. However, since the DAISY cohort is selected to be at increased genetic risk of type 1 diabetes, and therefore is not expected to be representative of the general population, and because we have an excellent comparison group embedded within our cohort (i.e. the higher-risk children who did not develop the outcome), it was not necessary to calculate SD scores to examine the association between body size and the development of IA and type 1 diabetes. Prospective follow-up of our cohort produced longitudinal data on size, which gave us the opportunity to examine velocity of growth. We note that our results regarding height velocity are consistent with what has been reported, even though other studies had used other statistical approaches and had used SD scores for their measure of height. Our analyses extend the previous findings by suggesting that the velocity of linear growth, rather than attained height or change in height (growth), may be the operative factor.

The mean difference in height growth velocity between DAISY children who did and did not develop IA is $0.18 \mathrm{~cm} /$ year (Table 2). It is not clear whether an increase in growth velocity of this small a magnitude is biologically relevant. However, the difference in height growth velocity between those autoimmune children who did and did not develop diabetes is much larger. IA-positive children who subsequently developed type 1 diabetes had a mean height growth velocity that was $0.54 \mathrm{~cm} /$ year greater than IA-positive DAISY children who did not develop type 1 diabetes. The consistency of the associations between greater height growth velocity and more rapid development of both IA and type 1 diabetes is intriguing. Our findings may offer preliminary support for the overload hypothesis [7], which suggests that high growth rate may exacerbate the autoim- mune process via beta cell overload. A causal link between rapid linear growth rate and greater risk of IA and subsequent type 1 diabetes development could be postulated. However, we acknowledge that greater height growth velocity may simply be a side effect of the underlying biological mechanisms that drive the autoimmune disease process.

One potential explanation for our findings is that increased linear growth velocity, perhaps associated with higher levels of IGF-I, may result in greater insulin secretion and insulin resistance, which have also been shown to be associated with greater IGF-I levels [34, 39, 40]. Insulin resistance may increase demands on the beta cell, and has been shown to precede type 1 diabetes development [41], especially when coupled with reduced insulin secretion [42]. However, there is currently little evidence supporting a role of insulin resistance in predicting IA. Finally, we cannot rule out a primary increase in insulin levels as the explanation for the more rapid linear growth. Chronic hyperinsulinaemia, perhaps because of a genetic tendency for hyperinsulinaemia, would result in both greater growth rate [43] and greater demands for insulin from the beta cell. The class III allele of the insulin INS gene, which is considered to be protective against type 1 diabetes [44], is also associated with lower BMI and lower fat mass in children with rapid infant growth [45], possibly through lower insulin secretion. Thus, exploration of the role of INS and its effect on insulin secretion may further our understanding of the association between rapid linear growth velocity and progression through the autoimmune disease process. In considering potential genetic influences on the observed associations between increased linear growth velocity and the autoimmune disease process, it is useful to note that statistical adjustment for HLA and family history did not materially affect these associations.

While a variety of biological mechanisms may be responsible for greater demand on the beta cell to produce insulin, the mechanism by which increased beta cell stress may lead to IA and type 1 diabetes may be more straightforward. Greater beta cell activity in response to high glucose concentrations has been linked with increased beta cell production of the GAD antigen [46]. In addition, more active beta cells have been shown to be more susceptible to cytokine damage [47, 48]. Thus, increasing beta cell activity, because of any cause, may trigger or exacerbate an autoimmune disease process. We are limited in this exploration by our lack of measurements of IGF-I, growth hormone, insulin, insulin resistance and beta cell function in DAISY children.

Our finding that shorter height was a weak risk factor for IA development was unexpected in light of the previously described associations between greater height and type 1 diabetes development [19, 20, 22, 24, 25]. One possible explanation of this unexpected finding is that shorter 
children may have experienced fetal or early life growth restriction, and may be more likely to grow more rapidly than their peers. Therefore, shorter height may simply proxy greater height growth velocity in the analysis of healthy children for the development of IA. We note that shorter height was not associated with earlier type 1 diabetes development in autoimmune children, which suggests that the biological mechanisms represented by shorter height may only be important at the earliest stages of the disease.

Childhood obesity and rapid weight gain, as measured by childhood BMI, weight growth velocity and BMI growth velocity, were not associated with earlier IA development in healthy children, or more rapid progression to type 1 diabetes in autoimmune children. These findings run contrary to previous reports $[18,20-23,25-28]$ which suggested that increased height, weight and/or BMI may be associated with type 1 diabetes or IA development. It is possible that the effects of obesity (weight or BMI) on the autoimmune disease process might be more evident in children without genetic risk of type 1 diabetes, and therefore may not be detectable in DAISY's higher-risk population. Also, the majority of these studies found associations with size or growth in very young ages, which was not the population of the current study. Our results suggest that the association with height velocity and type 1 diabetes is present at later ages in childhood. We are not able to make any inferences regarding the role of height growth velocity in the risk of IA and type 1 diabetes in children under the age of 2 years.

In conclusion, greater height growth velocity is either directly involved, or correlated with unmeasured factors involved, in the natural evolution from genetic susceptibility to autoimmunity and type 1 diabetes development in pre-pubertal children. Our results support further exploration of the biological mechanisms underlying the association between rapid linear childhood growth rate, IA development and progression to type 1 diabetes.

Acknowledgements This research was supported by National Institutes of Health grants R01-DK49654, DK32493, the Diabetes Endocrine Research Center, Clinical Investigation \& Bioinformatics Core P30 DK 57516 and the General Clinical Research Centers Program, National Center for Research Resources M01RR00069.

Duality of interest The authors declare that there is no duality of interest associated with this manuscript.

\section{References}

1. Johnston C, Millward BA, Hoskins P, Leslie RD, Bottazzo GF, Pyke DA (1989) Islet-cell antibodies as predictors of the later development of type 1 (insulin-dependent) diabetes. A study in identical twins. Diabetologia 32:382-386
2. Bonifacio E, Bingley PJ, Shattock M et al (1990) Quantification of islet-cell antibodies and prediction of insulin-dependent diabetes. Lancet 335:147-149

3. Onkamo P, Vaananen S, Karvonen M, Tuomilehto J (1999) Worldwide increase in incidence of Type I diabetes - the analysis of the data on published incidence trends. Diabetologia 42:13951403

4. EURODIAB ACE Study Group (2000) Variation and trends in incidence of childhood diabetes in Europe. EURODIAB ACE Study Group. Lancet 355:873-876

5. Pundziute-Lycka A, Dahlquist G, Nystrom L et al (2000) The incidence of Type 1 diabetes has not increased but shifted to a younger age at diagnosis in the 0-34 years group in Sweden 1983 to 1998. Diabetologia 45:783-791

6. Weets I, de Leeuw IH, Du Caju MVL et al (2002) The incidence of type 1 diabetes in the age group 0-39 years has not increased in Antwerp (Belgium) between 1989 and 2000: evidence for earlier disease manifestation. Diabetes Care 25:840-846

7. Dahlquist $G$ (2006) Can we slow the rising incidence of childhood-onset autoimmune diabetes? The overload hypothesis. Diabetologia 49:20-24

8. Wilkin TJ (2001) The accelerator hypothesis: weight gain as the missing link between type I and type II diabetes. Diabetologia 44:914-922

9. Knip M, Reunanen A, Virtanen SM, Nuutinen M, Viikari J, Akerblom HK (2008) Does the secular increase in body mass in children contribute to the increasing incidence of type 1 diabetes? Pediatr Diabetes 9:46-49

10. Waldhor T, Schober E, Rami B (2003) Regional distribution of risk for childhood diabetes in Austria and possible association with body mass index. Eur J Pediatr 162:380-384

11. Dabelea D, D'Agostino RB, Mayer-Davis EJ et al (2006) Testing the accelerator hypothesis: body size, beta-cell function, and age at onset of type 1 (autoimmune) diabetes. Diabetes Care 29:290294

12. Betts P, Mulligan J, Ward P, Smith B, Wilkin TJ (2004) Increasing body weight predicts the earlier onset of insulin-dependent diabetes in childhood: testing the 'accelerator hypothesis' (2). Diabet Med 22:144-151

13. Kibirige M, Metcalf B, Renuka R, Wilkin TJ (2003) Testing the accelerator hypothesis: the relationship between body mass and age at diagnosis of type 1 diabetes. Diabetes Care 26:2865-2870

14. Knerr I, Wolf J, Reinehr $\mathrm{T}$ et al (2005) The 'accelerator hypothesis': relationship between weight, height, body mass index and age at diagnosis in a large cohort of 9,248 German and Austrian children with type 1 diabetes mellitus. Diabetologia 48:2501-2504

15. O'Connell MA, Donath S, Cameron FJ (2007) Major increase in type 1 diabetes: no support for the Accelerator Hypothesis. Diabet Med 24:920-923

16. Porter JR, Barrett TG (2004) Braking the accelerator hypothesis? Diabetologia 47:352-356

17. Giménez M, Aguilera E, Castell C, de Lara N, Nicolau J, Conget I (2007) Relationship between BMI and age at diagnosis of type 1 diabetes in a Mediterranean area in the period of 1990-2004. Diabetes Care 30:1593-1595

18. Bruining GJ (2000) Association between infant growth before onset of juvenile type-1 diabetes and autoantibodies to IA-2. Netherlands Kolibrie Study Group of Childhood Diabetes. Lancet 356:655-656

19. DiLiberti JH, Carver K, Parton E, Totka J, Mick G, McCormick K (2002) Stature at time of diagnosis of type 1 diabetes mellitus. Pediatrics 109:479-483

20. EURODIAB Substudy 2 Study Group (2002) Rapid early growth is associated with increased risk of childhood type 1 diabetes in various European populations. Diabetes Care 25:1755-1760 
21. Hypponen E, Kenward MG, Virtanen SM et al (1999) Infant feeding, early weight gain, and risk of type 1 diabetes. Childhood Diabetes in Finland (DiMe) Study Group. Diabetes Care 22:19611965

22. Hypponen E, Virtanen SM, Kenward MG, Knip M, Akerblom HK (2000) Obesity, increased linear growth, and risk of type 1 diabetes in children. Diabetes Care 23:1755-1760

23. Johansson C, Samuelsson U, Ludvigsson J (1994) A high weight gain early in life is associated with an increased risk of type 1 (insulin-dependent) diabetes mellitus. Diabetologia 37:91-94

24. Larsson HE, Hansson G, Carlsson A et al (2008) Children developing type 1 diabetes before 6 years of age have increased linear growth independent of HLA genotypes. Diabetologia 51:1623-1630

25. Ljungkrantz M, Ludvigsson J, Samuelsson U (2008) Type 1 diabetes: increased height and weight gains in early childhood. Pediatr Diabetes 9:50-56

26. Pundziute-Lycka A, Persson LA, Cedermark G et al (2004) Diet, growth, and the risk for type 1 diabetes in childhood: a matched case-referent study. Diabetes Care 27:2784-2789

27. Viner RM, Hindmarsh PC, Taylor B, Cole TJ (2008) Childhood body mass index (BMI), breastfeeding and risk of Type 1 diabetes: findings from a longitudinal national birth cohort. Diabet Med 25:1056-1061

28. Couper JJ, Beresford S, Hirte C et al (2009) Weight gain in early life predicts risk of islet autoimmunity in children with a firstdegree relative with type 1 diabetes. Diabetes Care 32:94-99

29. Rewers M, Bugawan TL, Norris JM et al (1996) Newborn screening for HLA markers associated with IDDM: diabetes autoimmunity study in the young (DAISY). Diabetologia. 39:807-812

30. Yu L, Rewers M, Gianani R et al (1996) Antiislet autoantibodies usually develop sequentially rather than simultaneously. J Clin Endocrinol Metab 81:4264-4267

31. Törn C, Mueller PW, Schlosser M, Bonifacio E, Bingley PJ, Participating Laboratories (2008) Diabetes Antibody Standardization Program: evaluation of assays for autoantibodies to glutamic acid decarboxylase and islet antigen-2. Diabetologia 51:846-852

32. Yu L, Robles DT, Abiru N et al (2000) Early expression of antiinsulin autoantibodies of humans and the NOD mouse: evidence for early determination of subsequent diabetes. Proc Natl Acad Sci U S A 97:1701-1706

33. Stene LC, Barriga K, Hoffman M et al (2006) Normal but increasing hemoglobin $\mathrm{A} 1 \mathrm{c}$ levels predict progression from islet autoimmunity to overt type 1 diabetes: Diabetes Autoimmunity Study in the Young (DAISY). Pediatr Diabetes 7:247-253

34. Moran A, Jacobs DR Jr, Steinberger J et al (1999) Insulin resistance during puberty: results from clamp studies in 357 children. Diabetes 48:2039-2044
35. Taylor SJ, Whincup PH, Hindmarsh PC, Lampe F, Odoki K, Cook DG (2001) Performance of a new pubertal self-assessment questionnaire: a preliminary study. Paediatr Perinat Epidemiol $15: 88-94$

36. Fitzmaurice GM, Laird NM, Ware JH (2004) Applied longitudinal analysis. Wiley, New Jersey, p 221

37. Sontag MK, Corey M, Hokanson JE et al (2006) Genetic and physiologic correlates of longitudinal immunoreactive trypsinogen decline in infants with cystic fibrosis identified through newborn screening. J Pediatr 149:650-657

38. Rolland-Cachera MF, Deheeger M, Maillot M, Bellisle F (2006) Early adiposity rebound: causes and consequences for obesity in children and adults. Int J Obes Relat Metab Disord 30:S11-S17

39. Hindmarsh PC, Matthews DR, Di Silvio L, Kurtz AB, Brook CG (1988) Relation between height velocity and fasting insulin concentrations. Arch Dis Child 63:665-666

40. Ong KK, Petry CJ, Emmett PM et al (2004) Insulin sensitivity and secretion in normal children related to size at birth, postnatal growth, and plasma insulin-like growth factor-I levels. Diabetologia 47:1064-1070

41. Xu P, Cuthbertson D, Greenbaum C, Palmer JP, Krischer JP, Diabetes Prevention Trial-Type 1 Study Group (2007) Role of insulin resistance in predicting progression to type 1 diabetes. Diabetes Care 30:2314-2320

42. Bingley PJ, Mahon JL, Gale EA, European Nicotinamide Diabetes Intervention Trial Group (2008) Insulin resistance and progression to type 1 diabetes in the European Nicotinamide Diabetes Intervention Trial (ENDIT). Diabetes Care 31:146-150

43. Hill DJ, Milner RD (1985) Insulin as a growth factor. Pediatr Res 19:879-886

44. Anjos S, Polychronakos C (2004) Mechanisms of genetic susceptibility to type I diabetes: beyond HLA. Mol Genet Metab 81:187-195

45. Heude B, Petry CJ, Avon Longitudinal Study of Parents Children (ALSPAC) study team, Pembrey M, Dunger DB, Ong KK (2006) The insulin gene variable number of tandem repeat: associations and interactions with childhood body fat mass and insulin secretion in normal children. J Clin Endocrinol Metab 91:27702775

46. Bjork E, Kampe O, Karlsson FA et al (1992) Glucose regulation of the autoantigen GAD65 in human pancreatic islets. J Clin Endocrinol Metab 75:1574-1576

47. Palmer JP, Helqvist S, Spinas GA et al (1989) Interaction of betacell activity and IL-1 concentration and exposure time in isolated rat islets of Langerhans. Diabetes 38:1211-1216

48. Mandrup-Poulsen T (1996) The role of interleukin-1 in the pathogenesis of IDDM. Diabetologia 39:1005-1029 